International

Medical Society

http://imedicalsociety.org

\title{
Validity and Concordance of Hypertension Self-Reported Among Elderly People

\section{Abstract}

Background: The detection of the validity and concordance of selfreported hypertension (HBP) becomes necessary to increase the reliability of the reported information, given that errors in determining the prevalence of the disease can influence the quality of information and, therefore, the plans of action on public health policies. To assess the validity and concordance of self-reported HBP in the elderly population they registered in the Family Health Strategy (FHS) in a city of the Northeastern Brazil.

Methods: This is a cross-sectional study conducted with individuals aged 60 or over registered in the FHS in the city of Campina GrandePB. To check the validity and reliability of the report, the sensitivity, specificity and positive predictive (PPV) and negative values (NPV) were calculated with respect to demographic and socioeconomic variables, lifestyle and self-reported morbidity. The Kappa test was used to verify the agreement between diagnosis and disease report. Statistical application SPSS 22.0 and 5\% significance level were used.

Results: The study included 420 of elderly people (68.3\% women). Excellent sensitivity (81.7\%), specificity (98.7\%), PPV (99.6\%) and moderate NPV (56.0\%) were observed, as well as substantial agreement of HBP report.

Conclusion: This study showed validity and substantial agreement of self-reported HBP among of elderly people, suggesting that selfreported morbidity can be used as a tool for the identification of HBP prevalence; thus, assisting health services in coping with the problem.

\section{Elaine Cristina Tôrres Oliveira1,} Tarciana Nobre de Menezes ${ }^{2}$

1 Core of Humanities, Social and Public Policy, State University of Health Sciences of Alagoas, Maceió, State of Alagoas, Brazil.

2 Department of Physiotherapy, State University of Paraíba, Campina Grande, State of Paraíba, Brazil.

\section{Contact information:}

\section{Elaine Cristina Tôrres Oliveira.}

Address: Rua Abidias Batista da Silva, 135, Indianópolis. CEP: 55024-157, Caruaru, Pernambuco, Brazil. Tel: (+55) 8199983.3330 .

\section{”laineoliv@hotmail.com}

\section{Keywords}

Elderly; Hypertension; Reproducibility of Tests. 


\section{Introduction}

Non-communicable chronic diseases (NCDs) are high burden of morbidity and mortality for health systems around the world and are of concern due to their high prevalence and expenses related to treatment [1]. For presenting long latency periods and multiple risk factors, coping with NCDs is a public health problem to be faced worldwide [2].

According to World Health Organization data, 38 million people die each year due to NCDs, and more than 14 million deaths occur at ages from 30 to 70 years, of which $85.0 \%$ are in developing countries [2]. In Brazil, the impact caused by NCDs follows the global trend, given that data from the National Health Survey (PNS), conducted in 2013, revealed that over $70.0 \%$ of deaths in the country were the result of NCDs [3].

One important risk factor for the development of the most prevalent NCDs, cardiovascular diseases, is hypertension (HBP) [4]. HBP constitutes a clinical and multifactorial syndrome characterized by increased blood pressure levels of blood vessels [5], being a growing public health concern due to its socio-economic consequences [4].

In Brazil, HBP has high prevalence, considering that the analysis of studies conducted in the country during the last three decades have shown that the disease affects approximately $31.0 \%$ of adults [4]. For the elderly population, systematic review identified that the prevalence of HBP in Brazil between 1980 and 2010 was around 68.0\% [6].

Such high prevalence and the magnitude of its consequences, surveillance, early detection and timely treatment of hypertension are necessary to reduce the advance of resulting morbidity and mortality [6]. The identification of the disease, as well as the knowledge of its representativeness at population level are essential for planning actions aimed at reducing the incidence of HBP-related diseases [7].

Population studies have used morbidity indicators to detect the prevalence of HBP [8-12]. This method has been shown to be feasible, inexpensive and easy to perform [13] because it uses as disease diagnosis a positive response on its presence [10]. Data analysis study from the National Health and Nutrition Examination Survey (NHANES-III) [14], held in United States observed by high sensitivity (71.0\%), specificity $(90.0 \%)$, positive $(72.0 \%)$ and negative predictive values (89.0\%) that self-reported HBP has validity as an indicator of disease prevalence.

The detection of the validity of this information, particularly among elderly people registered by the Family Health Strategy (FHS), becomes necessary to increase the reliability of the reported information. Whereas the FHS represents the model of reorganization of primary health care in Brazil and among its duties is the care to chronic diseases, it is important to note the validity and agreement of the selfreported HBP, given that errors in determining the prevalence of the disease can influence the quality of information and therefore the action plans of public health policies [15].

Therefore, this study aimed to verify the validity and agreement between clinical diagnosis and selfreported HBP in the elderly population registered by the FHS of a city in Northeastern Brazil.

\section{Material and Methods}

This is a home-based cross-sectional study with primary data collection, with individuals aged 60 or more registered in the FHS of the city of Campina Grande-PB. Exclusion criteria are: i) those who had severe clinical weakness without therapeutic possibilities, i.e. end-stage individuals; ii) those who were absent from the municipality during field research in the FHS coverage area in which they were registered.

The Family Health Strategy Program is seen as a strategy for reorienting the health care model through the implementation of multidisciplinary teams in primary healthcare units. The teams work in the promotion, prevention, recovery and rehabilitation of individuals and community [16]. 
With about 385, 000 inhabitants, Campina Grande is the second most populous city in the State of Paraíba. At the time of data collection, there were 23, 416 older adults enrolled in 63 family health teams distributed in six health districts of the city at the time of data collection. To calculate the sample, an estimated prevalence of the outcomes of at least $25.0 \%$ with $95.0 \%$ confidence limit was used, assuming a $6.0 \%$ error. Since the sample has been obtained by conglomerates, sample correction was held $(2,1)$, resulting in a sample of 420 elderly proportion to each Health District.

The selection of subjects occurred through draw in each Health District of the Basic Family Health Unit (BFHU), totaling six BFHU randomly selected, in which the total number of older adults was calculated. The sample selection was as follows: a random selection of each Health District of a Family Basic Health Unit (BFHU) and counting of the total number of older adults registered in the unit were initially performed. The proportion of elderly people by BFHU to be investigated was later calculated, taking into account the total number of subjects in all BFHU selected. Given this proportion, the number of individuals to be interviewed per BFHU was determined. Thus, in the six BFHU selected, the following proportions (numbers) of elderly people were interviewed: $9.6 \%$ (40) 11.4\% (48) 14.5\% (61) $8.6 \%$ (36) $43.3 \%$ (182) and $12.6 \%$ (53), totaling 420 subjects.

After obtaining the number of individuals being investigated per BFHU, a systematic random selection of individuals was carried out by preparing a list with the names of all registered individuals. The number of subjects to be skipped to obtain to the next subject of the list to be interviewed was defined as the ratio between the total number of individuals registered and the number of individuals to be interviewed in that BFHU, thus generating the number five. Thus, at each subject selected, four subjects of the list were skipped. The $5^{\text {th }}$ subject was selected, and so on.
Data collection was performed in the home of individuals by three pairs of properly trained healthcare undergraduate students. Data collected were aimed to obtain information on the following variables:

- Demographic and socioeconomic: gender, age group (60-69 years, 70-79 years, 80 and over), color (white, nonwhite), years of schooling (illiterate, 1-4 years, 5-8 years, 9 years and over), marital status (single, married, widowed, separated), number of residents per household (single, 2, 3-5, 6 or more), socioeconomic level (A/B, C and D/E) Socioeconomic status was assessed through a questionnaire that consists of an "Economic Classification Criterion" ABA/ANEP/ABIPEME, consisting of data such as level of education and family ownership items. Each information refers to a number of points and, in the end, a score was generated, which in the economic stratification scale corresponds to the economic class to which the individual belongs (A1, A2, B1, B2, C, D, E) [17]. For statistical purposes, the classification has been redefined, and economic classes were grouped as: A/B, C and D/E.

- Life Habits: included information about smoking (never smoked, current smoker, exsmoker), alcohol consumption (never, daily, weekly, occasional or have consumed but no more) and regular physical activity (yes or no). Those who reported never having used cigarettes were considered who never smoked, current smokers were those who reported tobacco use (regardless of time and amount of use) and former smokers were those who reported having made use of the substance but no longer at the time of the study [18]. Those who reported never drank alcoholic beverages were considered individuals who never drank the substance. Those who reported alcohol consumption were classified 
according to the intake frequency, which may be daily, weekly and occasional, regardless of time and volume ingested [19]. Those who reported having used alcohol but no longer at the time of the study were considered former drinkers. Active individuals were those who practiced some kind of physical activity at least three times a week for at least thirty minutes [20]. Thus, individuals were classified as performing regular physical activity or not.

- Number of self-reported morbidities: includes information on the number of NCD reported by survey participants by the question: "Has a doctor or other health professional told you that you have a particular disease?" The answers were limited to eight chronic diseases (HBP, arthritis/arthrosis/rheumatism, heart problem, diabetes, osteoporosis, chronic lung disease, embolism/stroke and malignancy) (none, 1-3, 4 or more). As category of the independent variable, answers concerning the presence of HBP were not considered.

- High blood pressure: to obtain this information, blood pressure (BP) was measured with a mercury sphygmomanometer and clinical stethoscope (BD®, Curitiba/PR, Brazil). The measurements, whenever necessary, were carried out 30 minutes after individuals have smoked, have had breakfast or fed. Three measurements were performed with twominute interval. For analysis, the average value of three measurements was used. Individuals with HBP were those with systolic blood pressure value $\geq 140 \mathrm{mmHg}$ and/or diastolic blood pressure value $\geq 90 \mathrm{mmHg}$ and/or those who made use of anti-hypertensive drugs [12].

- Self-reported hypertension: includes information on the answer to the question "Has a doctor or other health professional told you that you have any of these diseases?" with eight response options, including HBP. Individuals who responded positively to the question about HBP were considered hypertensive.

\section{Statistical analysis}

The analysis and statistical information were obtained with the help of the statistical application SPSS 22.0 (SPSS Inc., Chicago, IL, USA). Initially, the prevalence of HBP measured and reported and their respective confidence intervals were checked (Cl of Wilson). To verify the validity and reliability of self-reported HBP, sensitivity, specificity, positive and negative predictive values were calculated for the diagnosis of the disease through BP measurement. The Kappa concordance test was used to verify the agreement between HBP diagnosis and self-reported HBP. For interpretation of the value found in the Kappa test, the concordance criteria of Landis and Koch was used [21], where value $<0.40$ represents reasonable agreement; value from 0.41 to 0.60 reflects moderate agreement, value from 0.61 to 0.80 is considered substantial agreement and kappa value from 0.81 to 1.00 is considered excellent agreement. In all analyses, significance level of $\alpha<5 \%$ was used.

\section{Ethical aspects}

All participants signed the Informed Consent Form after receiving verbal and written explanations regarding the study. The largest study, of which this is part, was approved by the Ethics Research Committee of the State University of Paraíba (UEPB) (Protocol. 0228.0.133.000-08).

\section{Results}

The study included 420 elderly people (68.3\% women). The average age of participants was 71.6 years $(S D=9.19)$. The prevalence of assessed and referred hypertension was, respectively, 80.9\% (Cl 95\%: 76.9-84.4) and 66.8\% (Cl 95\%: 61.7-70.7). 
Seeking to verify the validity of the self-reported HBP in relation to the gold standard, this study noted that the report of individuals about the disease showed excellent sensitivity, 81.7\% (Cl 95\%: 77.285.5), excellent specificity, 98.7\% (Cl 95\%: 93.299.8), excellent positive predictive value, $99.6 \%(\mathrm{Cl}$ 95\%: 98.0-100.0) and moderate negative predictive value, $56.0 \%$ (Cl 95\%:47.8-63.9).

When checking the answer to "Has a doctor or other health professional told you that you have any of these diseases?", including hypertension, subs- tantial agreement between report and the clinical diagnosis of hypertension among individuals was observed, considering the values found by the Kappa test (Kappa $=0.623 ; p<0.001)$.

Information on sensitivity, specificity, and positive and negative predictive values of self-reported HBP according to the study variables are shown in Table 1, which also shows that the sensitivity of the self-reported HBP was 100.0\% (CI 95\%: 87.5 -100.0) among men, 86.4\% (Cl 95\%: 79.1-91.5) among individuals aged $70-79$ years, $83.9 \%(\mathrm{Cl}$

Table 1. Sensitivity, specifivity, and predictive values of self-reported hypertension by sociodemographic, life habits and number of self-reported morbidities variables, Campina Grande, Paraíba, Brazil.

\begin{tabular}{|c|c|c|c|c|}
\hline Variables & Sensitivity, \% (95\% Cl) & Specificity, \% (95\% CI) & PPV, \% (95\% CI) & NVP, \% $(95 \% \mathrm{Cl})$ \\
\hline \multicolumn{5}{|l|}{ Sex } \\
\hline Male & $100.0(87.5-100.0)$ & $72.6(63.5-80.2)$ & $100.0(92.2-100.0)$ & $48.2(35.7-61.0)$ \\
\hline Female & $85.8(80.8-89.7)$ & $98.1(90.1-99.7)$ & 99.5 (97.2-99.9) & $61.2(50.5-70.8)$ \\
\hline \multicolumn{5}{|l|}{ Age } \\
\hline 60-69 years & $78.1(70.9-83.9)$ & $97.3(89.3-99.6)$ & $99.2(95.5-100.0)$ & $58.5(47.7-68.6)$ \\
\hline 70-79 years & $86.4(79.1-91.5)$ & $100.0(81.6-100.0)$ & $100.0(96.4-100.0)$ & $51.5(35.2-67.5)$ \\
\hline$\geq 80$ years & $81.8(70.8-89.3)$ & $100.0(78.5-100.0)$ & $100.0(93.4-100.0)$ & $53.5(35.5-71.2)$ \\
\hline \multicolumn{5}{|l|}{ Skin color } \\
\hline White & $83.9(77.6-88.7)$ & $97.4(86.8-99.5)$ & $99.3(96.1-99.9)$ & $58.5(46.3-69.6)$ \\
\hline Non-white & $79.5(72.9-84.9)$ & $100.0(91.4-100.0)$ & $100.0(97.2-100.0)$ & $53.9(42.8-64.7)$ \\
\hline \multicolumn{5}{|l|}{ Marital status } \\
\hline Married & $80.8(74.6-85.8)$ & $98.0(89.3-99.6)$ & 99.3 (96.4-99.9) & $57.1(46.5-67.2)$ \\
\hline Single & $71.4(50.0-86.2)$ & $100.0(56.5-100.0)$ & $100.0(79.6-100.0)$ & $45.4(21.3-72.0)$ \\
\hline Widowed & $84.7(76.8-90.2)$ & $100.0(84.5-100.0)$ & $100.0(96.1-100.0)$ & $55.3(39.7-69.8)$ \\
\hline Separated & $84.2(62.4-94.5)$ & $100.0(56.5-100.0)$ & $100.0(80.6-100.0)$ & $62.5(30.6-86.3)$ \\
\hline \multicolumn{5}{|l|}{ SEL } \\
\hline$A / B$ & $82.8(76.0-88.0)$ & $100.0(86.7-100.0)$ & $100.0(97.0-100.0)$ & $49.0(35.9-62.3)$ \\
\hline C & $81.5(74.4-87.0)$ & $97.8(88.7-99.6)$ & $99.2(95.4-99.8)$ & $62.5(50.9-72.8)$ \\
\hline $\mathrm{D} / \mathrm{E}$ & $78.6(64.1-88.3)$ & $100.0(70.1-100.0)$ & $100.0(89.6-100.0)$ & $50.0(29.0-71.0)$ \\
\hline \multicolumn{5}{|c|}{ Living in the household } \\
\hline 2 & $82.8(73.5-89.3)$ & 93.7 (71.7-99.0) & 98.6 (92.6-100.0) & $50.0(33.1-6.8)$ \\
\hline 1 & $63.2(41.0-80.8)$ & $100.0(56.5-100.0)$ & $100.0(75.7-100.0)$ & $41.7(19.3-68.0)$ \\
\hline $3-5$ & 81.9 (75.4-86.9) & $100.0(91.6-100.0)$ & $100.0(97.3-100.0)$ & $57.3(46.1-68.2)$ \\
\hline$\geq 6$ & $85.5(74.7-92.2)$ & $100.0(81.6-100.0)$ & $100.0(93.2-100.0)$ & $65.4(46.2-80.6)$ \\
\hline
\end{tabular}




\begin{tabular}{|c|c|c|c|c|}
\hline Variables & Sensitivity, \% (95\% Cl) & Specificity, \% (95\% CI) & PPV, \% (95\% Cl) & NVP, \% $(95 \% \mathrm{Cl})$ \\
\hline \multicolumn{5}{|l|}{ Years of study } \\
\hline Illiterate & $78.5(69.1-85.6)$ & $100.0(82.4-100.0)$ & $100.0(95.0-100.0)$ & $47.4(32.5-62.7)$ \\
\hline 1 to 4 years & $85.6(79.0-90.4)$ & $97.4(86.5-99.5)$ & $99.2(95.6-100.0)$ & $63.8(50.9-74.9)$ \\
\hline 5 to 8 years & $77.3(66.7-85.3)$ & $100.0(83.2-100.0)$ & $100.0(93.8-100.0)$ & $52.8(37.0-68.0)$ \\
\hline 9 years or more & $84.0(65.3-93.6)$ & $100.0(56.5-100.0)$ & $100.0(84.5-100.0)$ & $55.6(26.7-81.1)$ \\
\hline \multicolumn{5}{|l|}{ Smoking } \\
\hline Never smoked & $84.9(78.2-89.8)$ & $100.0(89.8-100.0)$ & $100.0(97.0-100.0)$ & $60.7(47.6-72.4)$ \\
\hline Current smoker & $63.4(48.1-76.4)$ & $93.7(71.7-98.9)$ & $96.3(81.7-99.3)$ & $50.0(33.1-66.8)$ \\
\hline Former smoker & $83.5(76.8-88.6)$ & $100.0(88.6-100.0)$ & $100.0(97.1-100.0)$ & $54.5(41.5-67.0)$ \\
\hline \multicolumn{5}{|l|}{ Alcohol consumption } \\
\hline Never & $82.9(76.8-87.6)$ & $97.3(86.2-99.5)$ & $99.4(96.5-99.9)$ & $52.9(41.2-64.3)$ \\
\hline Daily & $33.3(6.1-79.2)$ & $*(*)$ & $100.0(20.6-100.0)$ & $0.0(0.0-65.8)$ \\
\hline Weekly & $60.0(23.1-88.4)$ & $100.0(34.2-100.0)$ & $100.0(43.8-100.0)$ & $50.0(15.0-85.0)$ \\
\hline Occasional & $82.9(68.7-91.5)$ & $100.0(72.2-100.0)$ & $100.0(89.8-100.0)$ & $58.8(36.0-78.4)$ \\
\hline Have consumed but & $81.5(73.0-87.8)$ & $100.0(89.0-100.0)$ & $100.0(95.6-100.0)$ & $62.0(48.1-74.1)$ \\
\hline \multicolumn{5}{|l|}{ RPA } \\
\hline Yes & $84.3(75.0-90.6)$ & $100.0(77.2-100.0)$ & $100.0(94.8-100.0)$ & $50.0(32.1-67.9)$ \\
\hline No & $80.9(75.6-85.2)$ & $98.5(92.0-99.7)$ & 99.5 (97.3-99.9) & $57.4(48.3-66.0)$ \\
\hline \multicolumn{5}{|l|}{ Number of NCDs } \\
\hline None & $0.0(0.0-11.7)$ & $100.0(90.8-100.0)$ & $* *(* *)$ & $56.7(44.8-67.9)$ \\
\hline 1 to 3 & $88.5(84.1-91.8)$ & 97.6 (87.7-99.6) & 99.6 (97.7-99.9) & $56.9(45.4-67.7)$ \\
\hline 4 or more & 95.1 (83.9-98.6) & $*\left({ }^{*}\right)$ & $100.0(91.0-100.0)$ & $0.0(0.0-65.8)$ \\
\hline
\end{tabular}

SEL: Socioeconomic level; RPA: Regular physical activity; NCD: non-communicable chronic disease. *: There were

95\%: 77.6-88.7) among white individuals, 84.7\% (Cl 95\%: 76.8-90.2) among widowed, 85.5\% (Cl 95\%: 74.7-92.2) among those who live with 5 or more people in home, 85.6\% (Cl 95\%: 79.0-90.4) who had $1-4$ years of schooling, $82.8 \%(\mathrm{Cl} 95 \%$ : 76.0-88.0) among those belonging to socioeconomic status $A / B$, 84.9\% (Cl 95\%: 78.2-89.8) among those who never smoked, 82.9\% (Cl 95\%: 76.887.7), among those who never drank alcoholic beverages and those who reported drinking occasionaIly (Cl 95\%: 68.7-91.5), 84.3\% (Cl 95\%: 75.0-90.6) among those who reported regular physical activity and 95.1\% (Cl 95\%: 83.9-98.6) among those who reported 4 or more NCDs (Table 1).
The specificity of self-reported hypertension was high for all variables studied, as shown in Table 1. With the exception of the specificity of self-reported hypertension among men (72.6\%; Cl 95\%: 63.580.2 ), all other variables presented specificity above $90.0 \%$.

Regarding the positive predictive value, this study showed proportion above $90.0 \%$ in all variables of real hypertensive individuals that reported the presence of hypertension. As for the negative predictive value, variation from $41.7 \%$ to $65.4 \%$ was observed among true normotensive individuals who reported no hypertension. 


\section{Discussion}

HBP is considered a public health problem and so has been the subject of investigations that seek to understand which factors are related to its development and increase in populations $[6,8,11$, $12,22]$. Due to the relationship between HBP and the emergence of cerebrovascular complications, identifying the knowledge that the individual has concerning the diagnosis of HBP is a key part in reducing morbidity and mortality caused by the disease.

This study showed lower prevalence of self-reported hypertension compared to the prevalence of measured HBP. This result corroborates the findings of other studies, both national $[15,22]$ and international $[9,14]$. The lower prevalence of reported hypertension compared to the prevalence of measured hypertension is a matter of concern in view of the possible complications that the disease may result, if proper measures to promote health and disease prevention are not taken.

Recognizing that the use of self-reported morbidity may be limited to the individual's ability to remember and accurately report information regarding their health morbidity [23], this study aimed to verify the validity of self-reported HBP among study participants and observed excellent sensitivity and specificity when compared to the gold standard (BP measurement). A similar result was observed in population-based study conducted in the country with older adults (60 and over), in which the sensitivity and specificity of self-reported HBP were respectively $77.1 \%$ and $93.4 \%$ [15].

The results found in this study suggests that the self-reported information has validity and substantial concordance to identify the prevalence of hypertension among elderly people, a condition that makes self-reported morbidity a tool for identifying the prevalence of the disease and can be used in the FHS. Studies that have checked the validity and agreement of self-reported HBP under the FHS were not found in literature; however, it was observed that there is still no consensus on the possibility of its use as a disease prevalence indicator [23].

This study also verified high sensitivity of self-reported HBP among men compared to women. This result differs from those found in literature, which predominantly women are more aware about their health and have better understanding of the hypertension diagnosis than men [13-15, 24]. Justifications pointed out in literature to explain differences in practices and health care between men and women reveal that for men, the demand and participation in health services are more difficult due to historical and cultural aspects and issues concerning the organization of services, such as opening hours coincident with working hours and lack of programs and actions aimed at the needs of men [25].

As this study was conducted with elderly individuals, a possible explanation for the higher sensitivity of self-reported HBP among men may be related to greater availability of time of individuals due to retirement and greater identification with health services due to the onset of chronic disease leading to greater participation in actions offered by health services.

This study also showed increased sensitivity of self-reported HBP among individuals aged 70-79, white, widowed, who lived with five or more people at home, with 1-4 years of schooling and belonging to socioeconomic classes A/B. Similar results were identified by other studies on the validity of selfreported HBP with regard to age [13], marital status [15], number of individuals living in the household15 and educational level $[15,22]$. These demographic factors are important in driving the planning of care for individuals and should be observed for better prescription of treatment and control of hypertension within the FHS.

These results differ from those found in literature on the sensitivity of self-reported HBP related to color [22] and socioeconomic status of individuals [18]. In population-based study conducted in São 
Paulo [22], sensitivity of $65.6 \%$ of self-reported HBP among whites and $78.2 \%$ among non-whites was identified. Regarding socioeconomic level, population-based study conducted in the city of Campina Grande [15] found sensitivity of self-reported HBP of $78.5 \%$ among individuals belonging to socioeconomic level $C$ and $76.0 \%$ among those belonging to level $A / B$.

There was high sensitivity of self-reported HBP among elderly subjects who had never smoked and among those who performed regular physical activity, results that do not resemble those found in literature $[13,22]$. Population study in the city of Pelotas [13] identified increased sensitivity of selfreported HBP among former smokers (88.7\%) and among sedentary individuals (87.2\%) compared to those who never smoked and those who performed physical activity. The reason for this increased sensitivity reported among individuals with better lifestyle habits regarding smoking and physical activity may be related to a better understanding of risk factors for the development of NCDs.

High sensitivity among individuals who never used alcohol or mentioned to drink occasionally the substance and among those who reported the presence of 4 or more NCDs was also observed in this study. Studies that have checked the validity and agreement of self-reported HBP with these variables were not found in literature. These results may be related to greater knowledge on the part of the present study elderly, about the risks of alcohol consumption and high blood pressure levels, as well as the event of high organic commitment due to the presence of several NCDs.

The sensitivity and specificity values found in this study show differences from those observed in other studies $[13-15,22]$. It is noteworthy that the results exceeded values found by population survey also held in the city of Campina Grande-PB [15], in which the sensitivity and specificity of selfreported HBP were $77.1 \%$ and $93.4 \%$, respectively. This difference in results may be related to the fact that the individuals of this research are enrolled in the FHS, the government proposal responsible for the reorganization of the healthcare model in Brazil.

Through the FHS, guidelines of the Reorganization Plan to Attention to Hypertension are implemented in order to link patients of this disease to health units, ensuring their systematic monitoring and treatment through health promotion, prevention complications and controlling the disease [26]. This fact may account for the occurrence of high sensitivity and specificity of self-reported HBP among individuals and highlights the importance of health care based on ascription of customers, territorialization, situational diagnosis and planning, which are principles outlined by the FHS.

It was observed in this research that $81.7 \%$ of individuals identified as hypertensive through BP measurement also reported the presence of the disease. However, $18.3 \%$ of individuals were identified with abnormal blood pressure, but did not report previous diagnosis of hypertension. The fact that patients do not know they have the disease is a concern due to complications if the disease is not treated and controlled. So, investigating what factors that would be involved to the lack of knowledge of the altered pressure levels is fundamental for the health care planning.

One of the results of this study that deserves attention refers to the proportion of true normotensive individuals who declared themselves as normotensive (NPV $=56.0 \%$ ). This result, considered low, may reflect a false diagnosis of hypertension, error that can occur when they the norms and standards for ensuring the disease diagnosis are disregarded. It is known that the BP measurement, even considered the gold standard for the diagnosis of hypertension, can be influenced by several factors such as those related to changes in equipment, environmental conditions at the time of measurement and individual conditions (bladder distension, white apron hypertension). Therefore, compliance with 
measurement standards (measurement standardization, standardization at different times, equipment calibration, the correct positioning of the patient and restrictions before measurement) can improve the quality of information and ensure the correct diagnosis of hypertension [5].

Another factor that may have influenced this low prevalence of NPV among older adults may be related to the control of blood pressure levels by pharmacological treatment and control of risk factors, a condition that influence individuals to consider the non-existence of the disease. Therefore, emphasizing the chronic nature of HBP should be a regular part of health care in order to guarantee effective disease control.

Given the above results, there was validity and substantial agreement of self-reported HBP among study subjects. These results suggest that self-reported morbidity can be used as a tool for the identification of hypertension prevalence and help health services in coping with the problem.

Validation of morbidity referred for HBP as prevalence indicator is legitimated because due to ease of obtaining information as a result of BP measurement, although recommended, need the training of evaluators, specialized equipment, appropriate facilities and measurement in more than one time for diagnostic closing, expensive financial and logistical conditions [14].

Another important factor on studies of validity and morbidity concordance is the possibility to identify individuals affected by HBP, but who do not know or recognize their health status, which information is relevant for effective disease control.

\section{Author Contributions}

Elaine Cristina Tôrres Oliveira participated in the analysis, interpretation and discussion of the data and the final review of the article.

Tarciana Nobre de Menezes participated in the design, coordination and guidance of the study, analysis, interpretation and discussion of the data and the final review of the article.

\section{Conflict of Interest}

The authors declare that there are no conflicts of interest.

\section{Financial Support}

This work was afforded by CNPq (Brazilian Research Funding Agency), Universal Edict 15/2007-Process N 479579/2007-5.

\section{References}

1. World Health Organization. Global status report on noncommunicable diseases 2010. Geneva: World Health Organization, 2011.

2 World Health Organization. Noncommunicable diseases country profiles 2014. Geneva: World Health Organization, 2014.

3. Instituto Brasileiro de Geografia e Estatística. Pesquisa Nacional de Saúde 2013. Percepção do estado de saúde, estilos de vida e doenças crônicas. Rio de Janeiro: IBGE, 2014.

4. Sociedade Brasileira de Cardiologia; Sociedade Brasileira de Hipertensão; Sociedade Brasileira de Nefrologia. VI Diretrizes Brasileiras de Hipertensão. Arq Bras Cardiol. 2010; 95:1-51.

5. National Institutes of Health. The Seventh Report of the Joint National Committee on Prevention, Detection, Evaluation, and Treatment of High Blood Pressure. Bethesda MD: National Institutes of Health, 2004.

6. Picon RV, Fuchs FD, Moreira LB, Riegel G, Fuchs SC. Trends in prevalence of hypertension in Brazil: a systematic review with meta-analysis. PLoS One. 2012; 7(10):1-10.

7. Magalhães MEC, Brandão AA, Pozzan R, Campana EMG, Fonseca FL, Pizzi OL et al. Prevenção da hipertensão arterial: para quem e quando começar? Rev Bras Hipertens. 2010; 17(2):93-7.

8. Brasil. Ministério da Saúde. Secretaria de Vigilância em Saúde. Secretaria de Gestão Estratégica e Participativa. Vigitel Brasil 2010: vigilância de fatores de risco e proteção para doenças crônicas por inquérito telefônico. Brasília: Ministério da Saúde, 2011.

9. Lloyd-Sherlock P, Beard J, Minicuci N, Ebrahim S, Chatterji S. Hypertension among older adults in lowand middle-income countries: prevalence, awareness and control. Int J Epidemiol. 2014; 43:116-28.

10. Mion Júnior D, Pierin AMG, Bensenor IM, Marin JCM, Costa KRA, Henrique LFO et al. Hipertensão Arterial na Cidade de São Paulo: Prevalência Referida por Contato Telefônico. Arq Bras Cardiol. 2010; 95(1):99-106. 
11. Zaitune MPA, Barros MBA, César CLG, Carandina L, Goldbaum M. Hipertensão arterial em idosos: prevalência, fatores associados e práticas de controle no Município de Campinas, São Paulo, Brasil. Cad Saude Publica. 2006; 22(2):285-294.

12. Zattar LC, Boing AF, Giehl MWC, d'Orsi E. Prevalência e fatores associados à pressão arterial elevada, seu conhecimento e tratamento em idosos no sul do Brasil. Cad Saude Publica. 2013; 29(3):507-521.

13. Chrestani MAD, Santos IS, Matijasevich AM. Hipertensão arterial sistêmica auto-referida: validação diagnóstica em estudo de base populacional. Cad Saude Publica. 2009; 25(11):2395-2406.

14. Vargas CM, Burt VL, Gillum RF, Pamuk ER. Validity of SelfReported Hypertension in the National Health and Nutrition Examination Survey III, 1988-19911. Prev Med. 1997; 26:678685.

15. Menezes TN, Oliveira ECT, Sousa-Ficher MA. Validity and concordance between self-reported and clinical diagnosis of hypertension among elderly residents in northeastern Brazil. Am J Hypertens. 2014; 27(2):215-221.

16. Brasil. (2016, January 20). Estratégia Saúde da Família. [cited 2016 Jan 20]. Available from: http://dab.saude.gov.br/portaldab/ ape esf.php

17. Associação Nacional de Empresas de Pesquisa. Critério de Classificação Econômica Brasil. São Paulo, 1999.

18. Lessa I, Magalhães L, Araújo MJ, Almeida Filho N, Estela A, Oliveira MMC. Hipertensão Arterial na População Adulta de Salvador (BA) - Brasil. Arq Bras Cardiol. 2006; 87(6):747-756.

19. Souza ARA, Costa A, Nakamura D, Mocheti LN, Stevanato PR, Ovando LA. Um estudo sobre hipertensão arterial sistêmica na cidade de Campo Grande, MT. Arq Bras Cardiol. 2007; 88(4):441-446.

20. Pate RR, Pratt M, Blair SN, Haskell WL, Macera CA, Bouchard $C$ et al. Physical activity and public health: a recommendation from the Centers for Disease Control and Prevention and the American College of Sports Medicine. JAMA. 1995; 273:402407.

21. Landis J, Koch G. The measurement of observer agreement for categorical data. Biometrics. 1977; 33:159-174

22. Selem SSC, Castro MA, César CLG, Marchioni DML, Fisberg RM. Validade da Hipertensão autorreferida associa-se inversamente com escolaridade em brasileiros. Arq Bras Cardiol. 2012; 100(1):52-59.

23. Gorber SC, Tremblay M, Campbell N, Hardt J. The accuracy of self-reported hypertension: a systematic review and metaanalysis. Curr Hypertens Rev. 2008; 4:36-62.
24. Thawornchaisit P, Looze F, Reid CM, Seubbsman S, Sleigh. Validity of self-reported hypertension: findings from the Thai Cohort Study compared to physician telephone interview. Glob J Health Sci. 2014; 6(2):1-11.

25. Couto MT, Pinheiro TF, Valença O, Machin R, Silva GSN, Gomes $\mathrm{R}$ et al. O homem na atenção primária à saúde: discutindo (in)visibilidade a partir da perspectiva de gênero. Interface (Botucatu). 2010; 14(33):257-270.

26. Brasil. Ministério da Saúde. Secretaria de Vigilância em Saúde. Departamento de Análise de Situação de Saúde. Plano de ações estratégicas para o enfrentamento das doenças crônicas não transmissíveis (DCNT) no Brasil 2011-2022. Brasília: Ministério da Saúde, 2011.
Publish in International Archives of Medicine

International Archives of Medicine is an open access journal publishing articles encompassing all aspects of medical science and clinical practice. IAM is considered a megajournal with independent sections on all areas of medicine. IAM is a really international journal with authors and board members from all around the world. The journal is widely indexed and classified Q1 in category Medicine. 